\title{
Pulmonary Fibrosis in Hermansky-Pudlak Syndrome
}

\author{
Glenn W. Vicary ${ }^{1}$, Yeidyly Vergne ${ }^{2}$, Alberto Santiago-Cornier ${ }^{2}$, Lisa R. Young ${ }^{3}$, and Jesse Roman ${ }^{1,4}$ \\ ${ }^{1}$ Division of Pulmonary, Critical Care and Sleep Disorders Medicine, Department of Medicine, and Department of Pharmacology and \\ Toxicology, University of Louisville School of Medicine, Louisville, Kentucky; ${ }^{2}$ Department of Public Health, Ponce Health Sciences \\ University, Ponce, Puerto Rico; ${ }^{3}$ Division of Allergy, Immunology, and Pulmonary Medicine, Department of Pediatrics, and Division \\ of Allergy, Pulmonary, and Critical Care Medicine, Department of Medicine, Vanderbilt University School of Medicine, Nashville, \\ Tennessee; and ${ }^{4}$ Louisville Robley Rex Veterans Affairs Medical Center, Louisville, Kentucky
}

\begin{abstract}
Hermansky-Pudlak syndrome (HPS) is a rare autosomal recessive genetic disorder characterized by oculocutaneous albinism and a bleeding diathesis due to platelet dysfunction. More than $50 \%$ of cases worldwide are diagnosed on the Caribbean island of Puerto Rico. Genetic testing plays a growing role in diagnosis; however, not all patients with HPS have identified genetic mutations. In Puerto Rico, patients with HPS are often identified shortly after birth by their albinism, although the degree of hypopigmentation is highly variable. Ten subtypes have been described. Patients with HPS-1, HPS-2, and HPS-4 tend to develop pulmonary fibrosis in Puerto Rico; $100 \%$ of patients with HPS-1 develop HPS-PF. HPS-PF and idiopathic pulmonary fibrosis are considered similar entities (albeit with distinct causes) because both can show similar histological disease patterns. However, in contrast to idiopathic pulmonary fibrosis, HPS-PF manifests much earlier, often at
\end{abstract}

$30-40$ years of age. The progression of HPS-PF is characterized by the development of dyspnea and increasingly debilitating hypoxemia. No therapeutic interventions are currently approved by the U.S. Food and Drug Administration for the treatment of HPS and HPS-PF. However, the approval of two new antifibrotic drugs, pirfenidone and nintedanib, has prompted new interest in identifying drugs capable of reversing or halting the progression of HPS-PF. Thus, lung transplantation remains the only potentially life-prolonging treatment. At present, two clinical trials are recruiting patients with HPS-PF to identify biomarkers for disease progression. Advances in the diagnosis and management of these patients will require the establishment of multidisciplinary centers of excellence staffed by experts in this disease.

Keywords: pulmonary fibrosis; Hermansky-Pudlak syndrome; oculocutaneous albinism; genetics

(Received in original form March 14, 2016; accepted in final form July 16, 2016)

Correspondence and requests for reprints should be addressed to Jesse Roman, M.D., Division of Pulmonary, Critical Care and Sleep Disorders Medicine, Department of Medicine, 550 South Jackson Street (3rd floor), University of Louisville, Louisville, KY 40202. E-mail: j.roman@louisville.edu

Ann Am Thorac Soc Vol 13, No 10, pp 1839-1846, Oct 2016

Copyright (C) 2016 by the American Thoracic Society

DOI: 10.1513/AnnalsATS.201603-186FR

Internet address: www.atsjournals.org

Pulmonary fibrosis is characterized by the accumulation of fibroblasts and the unrestrained chaotic expression and deposition of connective tissue matrices leading to effacement of the pulmonary architecture with loss of lung function. Environmental factors (e.g., asbestos and silica exposure), genetic factors (e.g., surfactant-related proteins and telomerase), and viral factors (herpesvirus) have been associated with the development of lung fibrosis, and other factors are believed to contribute to its progression (e.g., allergens, tobacco). However, pulmonary fibrosis often occurs in subjects where a cause cannot be identified (1-6).
Despite the growing association of genetics with pulmonary fibrosis, the mechanisms by which abnormalities in these genes lead to alterations in cellular functions; extracellular matrix expression, deposition and degradation; production of profibrotic growth factors; and, ultimately, disruption of lung homeostasis and pulmonary fibrosis remain poorly understood.

One genetic disorder associated with a high prevalence of pulmonary fibrosis is the Hermansky-Pudlak syndrome (HPS), a rare autosomal recessive disorder characterized by oculocutaneous albinism, bleeding diathesis, granulomatous colitis, and, in many cases, pulmonary fibrosis. HPS affects approximately 500,000 to $1,000,000$ people worldwide, and has been reported in individuals from India, Japan, China, the United Kingdom, Western Europe, Pakistan, Canada, and the United States $(7,8)$. The international HPS Network registry also includes patients from Israel, Australia, Hungary, Mexico, Brazil, Peru, Qatar, and Bolivia, among others.

Although HPS is a rare disease, it is relatively common in Puerto Rico, where the prevalence of HPS-1 is estimated to be about 1 in 1,800 people in the northwest region of the island, accounting for 
approximately $50 \%$ of all cases globally (9). Unfortunately, the average life expectancy of patients with HPS is $40-50$ years.

There are currently no effective treatments, with more than $70 \%$ of patients dying of complications directly related to the disease (10).

Here, we summarize the current understanding of the pathogenesis of HPS and its clinical manifestations and management, while discussing discoveries that might lead to the identification of potential targets for intervention and effective therapies in the future. This review is intended to raise awareness about pulmonary fibrosis in HPS, and to prompt interest in further research in this syndrome, research that could also hold the key for understanding more common pulmonary fibrosing disorders.

\section{Genetic and Functional Abnormalities}

HPS was first described in 1959 by Dr. Frantisek Hermansky and Dr. Paulus Pudlak, who identified two patients with oculocutaneous albinism and bleeding diathesis in Czechoslovakia (11). HPS is a non-sex-linked autosomal recessive disorder with no known disease manifestations in carriers. Nine types of HPS have been defined on the basis of nine unique genes (Table 1) and distinguished by their signs, symptoms, and genetic cause; and in most cases, each subtype has more than one variant $(8,12-14)$; a tenth HPS type has also surfaced. HPS-1 is the most common and generally severe subtype. HPS-2 and HPS-4 also have severe manifestations and HPS-10 has neurological changes, while patients with the other variants (HPS-3, HPS-5-HPS-9) generally manifest somewhat milder symptoms (15).

In Puerto Rico, HPS- 1 and HPS- 3 are the most common subtypes. This is because certain populations in Puerto Rico were established by a small number of individuals who carried the silent gene (founder effect) (9). One in 21 Puerto Ricans in the northwest of the island are carriers of the gene mutation ( $>160,000$ people) (16). Thus, it is estimated that seven or eight children with HPS will be born on the island each year (9). In Puerto Rico, HPS-1 arises mainly as a result of a duplication/ frameshift (16 base pairs) on exon 15 of the HPS 1 gene, accounting for $45 \%$ of all HPS cases globally and most cases on the island $(9,17)$. Outside of Puerto Rico, HPS- 1 is caused by various mutations within the HPS1 gene loci (18). Another 25\% of HPS cases on the island occur from a deletion (3,904 base pairs) in HPS3. HPS3 is believed to have developed in the 1880 s1890 s in the central mountainous region of Puerto Rico $(9,17,19)$. Consistent with the genetic drift expected over hundreds of years, more recent studies have suggested that carrier frequencies for HPS1 and HPS3 are similar across Puerto Rico (9, 20).

Exactly how the genetic mutations in HPS genes lead to all manifestations of the disease is unknown. HPS genes encode HPS proteins, which form complexes termed biogenesis of lysosome-related organelles complexes (BLOCs) (Figure 1) (21-23).

Table 1. Human Hermansky-Pudlak syndrome variants

\begin{tabular}{lllcc}
\hline $\begin{array}{l}\text { Human } \\
\text { Type }\end{array}$ & Gene & NCBI RefSeq & $\begin{array}{c}\text { Human } \\
\text { Chromosome Location }\end{array}$ & $\begin{array}{c}\text { Protein } \\
\text { Complex }\end{array}$ \\
HPS1 & HPS1 & NM_000195 & $10 q 24.2$ & BLOC-3 \\
HPS2 & AP3B1 & NM_003664 & $5 q 14.1$ & AP-3 \\
HPS3 & HPS3 & NM_032383 & $3 q 24$ & BLOC-2 \\
HPS4 & HPS4 & NM_022081 & $22 q 12.1$ & BLOC-3 \\
HPS5 & HPS5 & NM_0181507 & $11 p 15.1$ & BLOC-2 \\
HPS6 & HPS6 & NM_024747 & $10 q 24.32$ & BLOC-2 \\
HPS7 & DTNBP1 & NM_032122 & $6 p 22.3$ & BLOC-1 \\
HPS8 & BLOC1S3 & NM_212550 & $19 q 13.32$ & BLOC-1 \\
HPS9 & BLOC1S6 & NM_012388 & $15 q 21.1$ & AP-3 \\
HPS10 & AP3D1 & NM_003938 & $19 p 13.3$ & ACOC \\
\hline
\end{tabular}

Definition of abbreviations: AP-3 = adaptor protein complex-3; BLOC-1, 2, 3 = biogenesis of lysosome-related organelles complex-1, 2, 3, respectively; HPS = Hermansky-Pudlak syndrome; NCBI RefSeq = National Center for Biotechnology Information Reference Sequence database. Adapted by permission from References 12 and 14.

Lysosome-related organelles (LROs) perform specialized functions in the sorting and trafficking of specific cargo. BLOC-3, a complex that includes the HPS1 and HPS4 proteins and others, functions as a Rab32/ 38 guanine nucleotide exchange factor; these are proteins capable of activating small GTPases, thereby affecting intracellular signaling and downstream targets.

HPS mutations impair the biogenesis and function of LROs, which explains some disease manifestations. For example, LRO dysfunction affecting pigment-producing cells (termed melanocytes) is responsible for albinism. Specifically, in melanocytes, activated Rab32/38 is needed for the transport of tyrosinase and tyrosinaserelated protein 1 (TYRP1) from early ribosomes to melanosomes; this likely represents a key step and its disruption has been shown to lead to the oculocutaneous manifestations of HPS-1 (24). In more than $80 \%$ of patients with HPS, this is manifested by lentigines, while a small percentage of patients may also develop solar keratosis, squamous cell, or basal cell carcinomas (16). Decreased pigmentation in the eyes causes legal blindness in most patients, as well as photophobia, impaired dark adaptation, and nystagmus.

Similarly, defects in platelet LROs lead to bleeding diathesis due to inhibition of the formation of platelet-dense bodies (25). In type II alveolar epithelial cells of the lung, Rab38 helps maintain lamellar body morphology and surfactant homeostasis (24). The role of this defect in the development of pulmonary fibrosis is not known, but it is intriguing to note that abnormalities in surfactant proteins have been identified in idiopathic pulmonary fibrosis and related interstitial lung disorders $(24,26,27)$. Disease mechanisms remain uncertain for the occurrence of granulomatous colitis, which has also been reported in approximately $15 \%$ of patients with HPS, not necessarily tracking with the occurrence of subtype risk for pulmonary fibrosis.

Accumulation of amorphous lipidprotein complexes called ceroids, which increase with age in patients with HPS, has been speculated to be a potential trigger for the development of tissue inflammation, possibly contributing to some of the multiorgan manifestations of HPS $(16,23,28,29)$. 


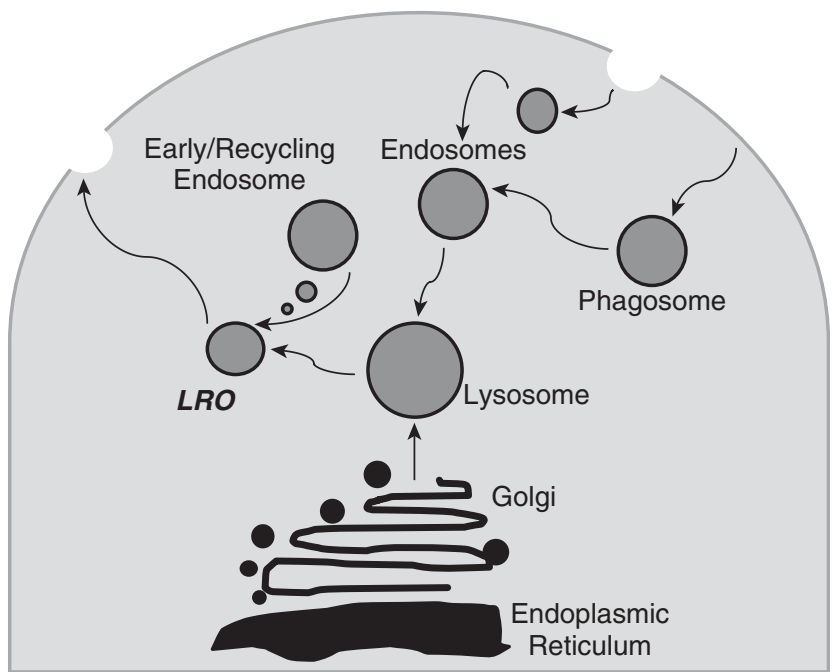

Figure 1. Lysosome-related organelles (LROs) are a group of cell type-specific subcellular compartments that share some features with endosomes and lysosomes, but also develop unique properties as they harbor specialized cargoes. Many of the clinical manifestations of HermanskyPudlak syndrome (HPS) are explained by abnormalities in the formation and trafficking of LROs, including albinism (melanosomes), bleeding (platelet-dense granules), and pulmonary fibrosis (likely related at least in part to abnormal lamellar body genesis in type II alveolar epithelial cells).

\section{Pulmonary Fibrosis: Clinical Features}

Only HPS-1, HPS-2, and HPS-4 are associated with the development of pulmonary fibrosis. In a joint statement of the American Thoracic Society and European Respiratory Society, HPS-related pulmonary fibrosis (HPS-PF) and idiopathic pulmonary fibrosis (IPF) are considered similar entities (albeit with distinct causes) because both can show similar histological patterns (30). IPF occurs spontaneously in most patients, but research has uncovered some genetic mutations in surfactant proteins, mucins, and telomerases that are considered relevant (1, 3-6). In contrast, $100 \%$ of patients with HPS- 1 develop HPS-PF (29).

Both HPS-PF and IPF are characterized by irreversible and progressive fibrosis of the lung parenchyma and interalveolar septa, ultimately leading to death from respiratory failure. Similar symptoms are found in HPS-PF and IPF, including increased dyspnea initially manifested as exercise intolerance that progresses to dyspnea at rest and the need for supplemental oxygen over time.

One intriguing, but important difference between IPF and HPS-PF is the age at which pulmonary fibrosis is detected. Spontaneous IPF manifests in patients mostly over age 50 years (this is not the case for familial IPF), whereas HPS-PF occurs much earlier (at age 30-40 yr). Another major difference is that the average survival time after diagnosis differs with IPF, carrying a dismal 3-year survival rate of $50 \%$, whereas patients with HPS live approximately 10 years after diagnosis (31, 32 ); this might reflect earlier ascertainment and not differing natural history.

\section{Pulmonary Fibrosis: Pathogenesis}

Current understanding of the pathogenesis of pulmonary fibrosis points to epithelial cell dysfunction as the inciting cause of the disease. Several intracellular trafficking processes might be affected, leading to endoplasmic reticulum stress and apoptosis caused by environmental exposure to injurious agents (e.g., viral infection, recurrent aspiration of gastric contents) or through genetic abnormalities (e.g., surfactant proteins). Injured or dysfunctional epithelial cells are proposed to promote the accumulation of fibroblasts that are responsible for the excessive deposition of extracellular matrices (33).

The origins of these fibroblasts are unclear, but combinations of mechanisms are hypothesized, including the transdifferentiation of epithelial cells (epithelial-mesenchymal transformation), the differentiation of fibrocytes and stem cells, and the proliferation of resident fibroblasts (34). Regardless of their source of origin, the interplay between dysfunctional epithelial cells and activated fibroblasts (also termed myofibroblasts because of their expression of smooth muscle cell markers) seems to drive unrestrained collagen deposition and tissue scarring. Underlying amplifying factors such as aging and epigenetic changes are thought to further perpetuate the progressive nature of pulmonary fibrosis (33).

There is a growing body of work dissecting the mechanisms of pulmonary fibrosis in HPS. HPS gene products are ubiquitously expressed and thus many cell types have been potentially implicated as contributors to the pathogenesis of HPS-PF. First, there is strong evidence that macrophage-mediated inflammation precedes pulmonary fibrosis in patients with HPS. Bronchoalveolar lavage fluid of patients with HPS-PF contained increased total cell counts and alveolar macrophages (35), at a time when patients still had relatively preserved lung function. Furthermore, alveolar macrophages from patients with HPS have been shown to be constitutively activated, expressing excess cytokines and chemokines when studied ex vivo (35).

Bronchoalveolar lavage fluid from patients with HPS contains elevated levels of several cytokines, including chemokine (C-C motif) ligand 2 (CCL2/monocyte chemotactic protein [MCP]-1), macrophage colony-stimulating factor (M-CSF), and granulocyte-macrophage colonystimulating factor (GM-CSF) (35).

Interestingly, elevation of CCL2 levels was directly associated with the progression of HPS-PF; a similar association has been observed in IPF and animal models of pulmonary fibrosis $(36,37)$.

Abnormalities in fibroblasts have also been reported, including increased expression of galectin-3, a $\beta$-galactosidebinding lectin with profibrotic effects (38). In addition, patients with HPS-PF have been found to have increased numbers of circulating CXCR4-positive fibrocytes compared with subjects with HPS without lung disease or healthy control subjects (39). Increasingly, as suggested for IPF, studies point to the type II alveolar epithelial cell as central in the pathogenesis of HPS pulmonary fibrosis. Lamellar bodies (responsible for producing surfactant 
proteins) are a type of LRO (27), making alveolar epithelial cells a good candidate for dysfunction in HPS.

\section{Murine Models}

As HPS lung tissue is limited in availability for research because of disease rarity and contraindication to lung biopsy because of the bleeding diathesis, much HPS research to date has been conducted in murine models, which also afford opportunities for access to cells and tissues, and genetic manipulations not possible in humans. Murine models of HPS reliably share many aspects of the human disease including hypopigmentation, deficiency of platelet-dense granules, and abnormalities of type II alveolar epithelial cells and alveolar macrophages (Tables 2 and 3). Mice have more than 16 different genes with HPS-like phenotypes (40), although many of the gene functions are unknown. At least six mouse models have the orthologous mutations to the human genes (41-46).

Interestingly, murine models of HPS-1 (Pale ear) and HPS-2 (Pearl) show activation of alveolar macrophages in the lung, but not in the blood or peritoneum $(47,48)$. Pale ear HPS-1 mice do not develop spontaneous fibrosis, but have higher baseline collagen deposition and show increased inflammation and collagen expression in response to silica challenge $(47,49,50)$. In response to bleomycin, HPS-1 and HPS-2 mice developed fibrosis significantly earlier and to a greater extent than wild-type mice (48). Also, higher levels of transforming growth factor (TGF)- $\beta$ were detected in bleomycin-treated HPS mice.

It is intriguing that spontaneous lung fibrosis does not occur in these singlemutant models, suggesting that other factors and secondary hits are required to develop the full manifestations of the disease. With aging, spontaneous fibrosis has been reported in an HPS double-mutant model, generated by mating HPS- 1 and HPS- 2 mice (51). Alveolar epithelial cell dysfunction in HPS remains under study, but publications implicate alveolar epithelial cell apoptosis $(51,52)$, chitinase-3-like- 1 and its receptors (53), and autophagy (54) as potential mechanisms. Macrophage-mediated inflammation is also present in HPS mouse models. However, murine bone marrow transplant studies have demonstrated that macrophage abnormalities and fibrotic

Table 2. Mouse models of Hermansky-Pudlak syndrome

\begin{tabular}{llc}
\hline Mouse Model & Mouse RefSeq & Mouse Chromosome Location \\
Pale ear & NM_019424 & Chr19 \\
Pearl & NM_009680 & Chr13 \\
Cocoa & NM_080634 & Chr13 \\
Light ear & NM_138646 & Chr5 \\
Ruby eye-2 & AF534396 & Chr7 \\
Ruby eye & NM_176785 & Chr19 \\
Sandy & NM_025772 & Chr13 \\
Zebrafish & NM_001025476 & Chr15 \\
Pallid & NM_019788 & Chr2 \\
Muted & NM_139063 & Chr13 \\
Cappuccino & NM_133724 & Chr5 \\
Mocha & NM_007460 & Chr10 \\
\hline
\end{tabular}

Definition of abbreviation: RefSeq = Reference Sequence database

Adapted by permission from Reference 14 .

susceptibility are likely due to epithelial dysfunction with type II alveolar cell death, not intrinsic macrophage defects (52).

This is important because it suggests that HPS-PF could be driven by more than just macrophage mutations. Collectively, these studies indicate the role of HPS mice as an experimental model for HPS disease, and identify mechanisms that are likely also relevant for other fibrosing lung diseases.

\section{Diagnosing HPS and HPS- Related Pulmonary Fibrosis}

The diagnosis of HPS includes the documentation of oculocutaneous albinism and platelet storage pool deficiency (29).

Patients with HPS are potentially identified shortly after birth by their albinism, although the degree of hypopigmentation is variable. Other individuals are not diagnosed until after experiencing other disease complications such as excessive bleeding after circumcision or easy bruising; more than $75 \%$ of patients have bruises at the time of clinical examination. Bleeding time is often quite prolonged, but is not recommended for diagnostic or screening because of poor specificity and lack of prognostic value (55). Ophthalmologists might be the first to suggest testing for HPS because of diminished vision, with transillumination of the iris in addition to nystagmus and strabismus.

Testing for HPS is currently limited by complexity, expense, and availability of

Table 3. Phenotype and cellular abnormalities in mouse models of Hermansky-Pudlak syndrome

Physiology/Cellular Abnormality

Hypopigmentation

Prolonged bleeding

Lung disease

Decreased lysosomal enzyme secretion (kidney)

Decreased CTL granule secretion

Dysregulated mast cell granule secretion

CD1d deficiency

NK cell dysfunction

Decreased proplatelet production

Night blindness

Susceptibility to anesthetics

Protection from atherosclerosis

Increased emperipolesis

Otolith deficiency

Hippocampal granule deficiency

Decreased life span

\section{Mouse HPS Gene(s)}

All
All
HPS1/HPS2 double mutant, Pldn
Most
Rab27a
HPS6
HPS2
HPS1, Pldn, rp
Rabggta
HPS2
Pldn, rp
HPS4, HPS6
Rabggta
Ap3d, Pldn, mu
Ap3d
Rabggta, HPS2, HPS3, Pldn

Definition of abbreviations: $\mathrm{CTL}=$ cytotoxic $\mathrm{T}$ lymphocyte; $\mathrm{NK}=$ natural killer.

Adapted by permission from Reference 12 . 
specialized diagnostics required for confirmation. The "gold standard" test for the platelet abnormality in HPS is analysis by whole-mount electron microscopy for the absence of dense bodies (56). Testing of platelet aggregation after platelet stimulation with adenosine diphosphate or epinephrine (using a platelet aggregometer) (57) provides a less specific alternative.

Genetic testing plays a growing role in diagnosis, and it is important for determining HPS subtype (and prognosis). Such assessments are also essential to determine the numbers of individuals with distinct HPS subtypes in any given community. Not all patients with HPS have identified genetic mutations, however, suggesting that there are additional HPS disease-causing genes to be discovered. Genetic testing has not been widely implemented for HPS because of the cost of next-generation sequencing (58). Genetic testing could be used to help identify specific mutations as the price of next-generation sequencing decreases. In the absence of genetic confirmation, patients with the classic manifestations of the syndrome (e.g., albinism with bleeding disorder, colitis, or pulmonary fibrosis) should be considered to have HPS unless proven otherwise.

A high level of suspicion is required to identify pulmonary fibrosis at an early age in patients with HPS-1, HPS-2, and HPS-4. Lung computed tomographic imaging is helpful in patients known to have HPS and who develop respiratory symptoms. The most common abnormalities in cases of minimal severity are interlobular septal thickening, reticular opacities, ground-glass opacities, and subpleural honeycombing. Bronchoscopy has been used for research purposes, but does not have proven benefits for the diagnosis of HPS-PF. In contrast to IPF, a lung biopsy is not recommended for patients with suspected HPS-PF because of the bleeding diathesis.

\section{Monitoring Progression of Pulmonary Fibrosis}

The progression of HPS-PF is characterized by the development of dyspnea and increasingly debilitating hypoxemia. Thus, it is recommended that all patients with HPS-1, HPS-2, and HPS-4 be evaluated for lung function during adolescence and yearly thereafter (29). Pulmonary physiology is best evaluated by pulmonary function tests, including diffusing capacity of the lung for carbon monoxide. Early evidence of pulmonary fibrosis might be manifested by a decrease in the FVC and lung volumes (indicating a restrictive defect) and reduced diffusing capacity of the lung for carbon monoxide, which is typical of fibrosing lung disorders. A 6-minute walk test, using a portable oximeter, should also be considered as hypoxemia may be detected only during exertion in early stages of the disease.

The progression of HPS-PF is also evaluated by high-resolution computed tomography. As the disease progresses, the predominant radiographic findings are seen within the lung periphery and progress toward the central portion of the lung. Characteristic abnormalities include ground-glass opacities, reticulation of interstitial spaces, and, in advanced disease, loss of lung volume, honeycombing, and traction bronchiectasis $(15,59,60)$.

As the disease advances, reticular opacities and subpleural honeycombing are present to a greater extent. In addition, a wider range of findings including bronchiectasis, peribronchovascular thickening, and pleural thickening has been reported. In severe cases, subpleural honeycombing and bronchiectasis are more common, and subpleural reticular opacities, ground-glass opacities, and peribronchovascular thickening are also present $(23,59,61)$. Thus, although the pattern of pulmonary fibrosis in HPS-PF may be similar to that observed in IPF, several findings are not consistent, such as groundglass opacification and pleural thickening (Figure 2).

\section{Clinical Management of Pulmonary Fibrosis}

At present, no therapeutic interventions are specifically designated by the U.S. Food and Drug Administration for the treatment of HPS and HPS-PF. Similar to IPF, corticosteroids have not shown clinical efficacy and are not recommended. Thus, until safe and effective treatment strategies are developed, lung transplantation may remain the only effective treatment $(20,59,62)$.

As is the case for IPF, treatment relies on preventive care and support as needed. Patients with hypoxemia should be provided supplemental oxygen. Infection prophylaxis is important; thus, influenza and 13-valent and 23-valent pneumococcal vaccinations are recommended, and administered with caution to avoid intramuscular bleeding. In addition, a 5-year polysaccharide booster vaccine may be beneficial (63).

Avoidance of cigarette smoke and other pulmonary irritants is critical, and daily exercise is recommended to avoid deconditioning. Patients with HPS should avoid unprotected eye and skin exposure to the sun because of their albinism.

Menometrorrhagia is common in women, but can be lessened with medication $(16,29)$. Further, patients with HPS should avoid aspirin and nonsteroidal antiinflammatory drugs, due to platelet inhibition. Extensive injuries should prompt a hospital visit and consultation with a hematologist.

The approval of two new antifibrotic drugs, pirfenidone and nintedanib, for the treatment of IPF has prompted new interest in identifying drugs capable of reversing or, at the very least, halting the progression of HPS-PF. It should be emphasized that these drugs are not curative, but instead appear to slow down the decline of lung fibrosis in IPF. Pirfenidone, a small molecule capable of inhibiting TGF- $\beta$, showed success in slowing pulmonary dysfunction in clinical trials with patients with IPF $(64,65)$.

Interestingly, ex vivo, pirfenidone showed significantly decreased inflammatory cytokines in the alveolar macrophages of patients with HPS (35). An initial clinical trial of pirfenidone in patients with HPS-1 showed no significant slowing of fibrosis progression by serial measurement of FVC (32). Secondary analysis of this patient population suggested that patients with an initial FVC value greater than $50 \%$ of expected had a significant decrease in the progression of pulmonary fibrosis. Disappointingly, a follow-up study of patients with HPS-1 and HPS- 4 with milder disease showed no significant benefit and was stopped prematurely, but it was likely underpowered (66). Future clinical studies will be needed in HPS to identify effective treatments.

Considering the genetic basis for the development of HPS, one would predict that gene transfer might be successful in treating this disease. In fact, others have used lentiviruses for the transfer of the HPS1 gene into human dermal melanocytes in vitro and shown correction of the expression and function of the HPS 1 gene in these cells (26). However, 


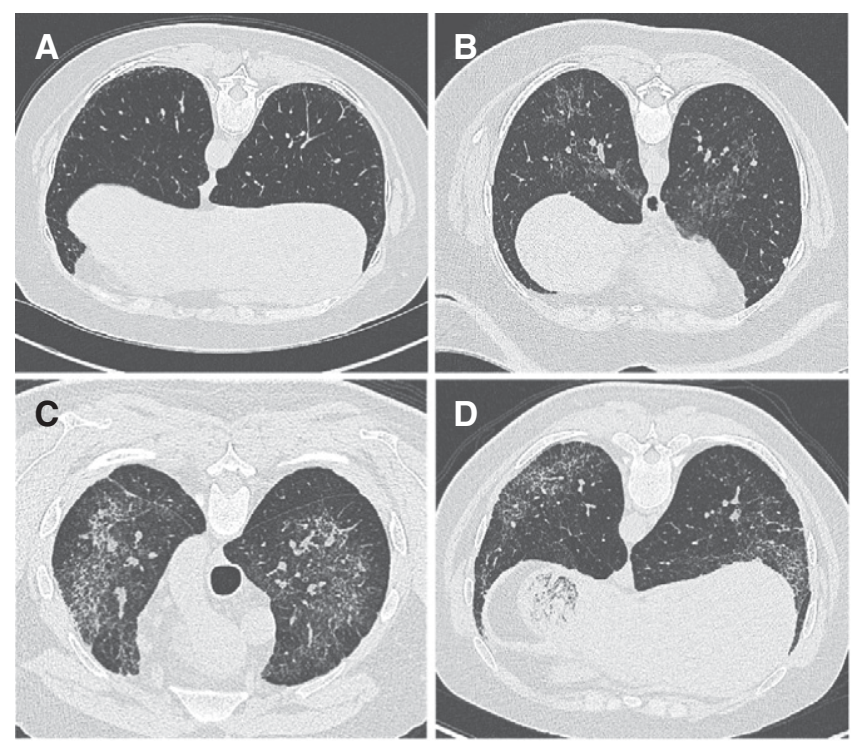

Figure 2. Examples of chest computed tomographic findings in subjects with Hermansky-Pudlak syndrome (HPS). (A) A scan of a 50-year-old patient with HPS-1 shows mild changes consistent with subpleural infiltrates. $(B)$ A scan of a 41-year-old patient with central infiltrates. $(C)$ Ground-glass opacification. $(D)$ Scans of a 31-year-old patient with mid- to upper lung infiltrates as well as subpleural honeycombing. The images shown are from patients who provided consent in the Rare Lung Diseases Consortium HPS study under Vanderbilt University IRB protocol number 150104.

difficulties in gene transfer methods in the lung, particularly to the alveolar epithelium, hamper progress in this area, and much still needs to be learned before gene therapy can be considered for potential correction of BLOC-3 dysfunction.

\section{Recommendations for Future Research}

The epidemiology, natural history, clinical heterogeneity, and best approach to pulmonary monitoring in this population remain insufficiently understood. Despite significant scientific advances, additional research is needed to identify the mechanisms by which the genetic mutations responsible for HPS result in the clinical manifestations of the syndrome. In vitro and ex vivo studies with tissue, cell, blood, bronchoalveolar lavage fluid, and other samples collected from patients, as well as in vivo studies in animal models, hold promise for determining relevant biological pathways for intervention.
Well-conducted placebo-controlled and randomized clinical trials will accelerate the evaluation of new antifibrotic agents and other interventions with therapeutic potential. Undoubtedly, the small number of patients affected by HPS will make large-scale studies difficult.

At present, two clinical trials are recruiting patients with HPS-PF to develop (it is hoped) better biomarkers for disease progression (NCT02368340, NCT00001456). Such investigations may lead to effective and safe therapies for HPS and its manifestations, especially pulmonary fibrosis. In the meantime, we must find ways to address the clinical needs of these patients.

The diagnosis, management, and follow-up of patients with HPS require the establishment of multidisciplinary centers of excellence staffed with experts in this area. In Puerto Rico, the increased incidence of HPS warrants the development of such a center. Considering that centers with capabilities for lung transplantation are not available in Puerto Rico, connections with centers in the United States with transplantation capability are important because this procedure is currently the only option for a significant number of patients with HPS-PF.

Author disclosures are available with the text of this article at www.atsjournals.org.

Acknowledgment: The authors thank Donna Appell and the Hermansky-Pudlak Syndrome Network for input and collaboration.

\section{References}

1 Ley B, Collard HR. Epidemiology of idiopathic pulmonary fibrosis. Clin Epidemiol 2013;5:483-492.

2 Kropski JA, Lawson WE, Blackwell TS. Right place, right time: the evolving role of herpesvirus infection as a "second hit" in idiopathic pulmonary fibrosis. Am J Physiol Lung Cell Mol Physiol 2012;302: L441-L444.

3 Selman M, Lin HM, Montaño M, Jenkins AL, Estrada A, Lin Z, Wang G, DiAngelo SL, Guo X, Umstead TM, et al. Surfactant protein A and B genetic variants predispose to idiopathic pulmonary fibrosis. Hum Genet 2003;113:542-550.

4 Thomas AQ, Lane K, Phillips J III, Prince M, Markin C, Speer M, Schwartz DA, Gaddipati R, Marney A, Johnson J, et al. Heterozygosity for a surfactant protein $\mathrm{C}$ gene mutation associated with usual interstitial pneumonitis and cellular nonspecific interstitial pneumonitis in one kindred. Am J Respir Crit Care Med 2002;165: 1322-1328.

5 Seibold MA, Wise AL, Speer MC, Steele MP, Brown KK, Loyd JE, Fingerlin TE, Zhang W, Gudmundsson G, Groshong SDgh, et al.
A common MUC5B promoter polymorphism and pulmonary fibrosis. N Engl J Med 2011;364:1503-1512.

6 Trăilă D, Mlădinescu OF, Oancea C, Tudorache V. Short telomeres in pulmonary fibrosis: from genetics to clinical significance. Pneumologia 2015;64:8, 11-13.

7 Yousaf S, Shahzad M, Kausar T, Sheikh SA, Tariq N, Shabbir AS, Ali M, Waryah AM, Shaikh RS, Riazuddin S, et al.; University of Washington Center for Mendelian Genomics. Identification and clinical characterization of Hermansky-Pudlak syndrome alleles in the Pakistani population. Pigment Cell Melanoma Res 2016;29:231-235.

8 Gahl WA, Huizing M. Hermansky-Pudlak syndrome. In: Pagon RA Adam MP, Ardinger HH, Wallace SE, Amemiya A, Bean LJH, Bird TD, Fong CT, Mefford HC, Smith RJH, et al., editors. GeneReviews [2000 Jul 24; updated 2014 Dec 11; accessed 2016 Aug 27]. Seattle, WA: University of Washington; 1993-2016. Available from: http://www. ncbi.nlm.nih.gov/pubmed/20301464

9 Santiago Borrero PJ, Rodriguez-Perez Y, Renta JY, Izquierdo NJ, Del Fierro L, Munoz D, Molina NL, Ramírez S, Pagán-Mercado G, Ortíz I, et al. Genetic testing for oculocutaneous albinism type 1 and 2 and Hermansky-Pudlak syndrome type 1 and 3 mutations in Puerto Rico. $J$ Invest Dermatol 2006;126:85-90. 
10 Witkop CJ, Almadovar C, Piñeiro B, Nuñez Babcock M. HermanskyPudlak syndrome (HPS): an epidemiologic study. Ophthalmic Paediatr Genet 1990;11:245-250.

11 Hermansky F, Pudlak P. Albinism associated with hemorrhagic diathesis and unusual pigmented reticular cells in the bone marrow: report of two cases with histochemical studies. Blood 1959;14: 162-169.

12 Li W, Rusiniak ME, Chintala S, Gautam R, Novak EK, Swank RT. Murine Hermansky-Pudlak syndrome genes: regulators of lysosome-related organelles. BioEssays 2004;26:616-628.

13 Wei ML. Hermansky-Pudlak syndrome: a disease of protein trafficking and organelle function. Pigment Cell Res 2006;19:19-42.

14 Sánchez-Guiu I, Torregrosa JM, Velasco F, Antón Al, Lozano ML, Vicente V, Rivera J. Hermansky-Pudlak syndrome: overview of clinical and molecular features and case report of a new HPS-1 variant. Hamostaseologie 2014;34:301-309.

15 Kelil T, Shen J, O'Neill AC, Howard SA. Hermansky-Pudlak syndrome complicated by pulmonary fibrosis: radiologic-pathologic correlation and review of pulmonary complications. J Clin Imaging Sci 2014; 4:59.

16 Witkop CJ, Nuñez Babcock M, Rao GH, Gaudier F, Summers CG, Shanahan F, Harmon KR, Townsend D, Sedano HO, King RA, et al. Albinism and Hermansky-Pudlak syndrome in Puerto Rico. Bol Asoc Med P R 1990;82:333-339.

17 Anikster Y, Huizing M, White J, Shevchenko YO, Fitzpatrick DL, Touchman JW, Compton JG, Bale SJ, Swank RT, Gahl WA, et al. Mutation of a new gene causes a unique form of Hermansky-Pudlak syndrome in a genetic isolate of central Puerto Rico. Nat Genet 2001; 28:376-380.

18 Carmona-Rivera C, Golas G, Hess RA, Cardillo ND, Martin EH, O’Brien K, Tsilou E, Gochuico BR, White JG, Huizing M, et al. Clinical, molecular, and cellular features of non-Puerto Rican Hermansky-Pudlak syndrome patients of Hispanic descent. J Invest Dermatol 2011;131: 2394-2400.

19 Oh J, Bailin T, Fukai K, Feng GH, Ho L, Mao JI, Frenk E, Tamura N, Spritz RA. Positional cloning of a gene for Hermansky-Pudlak syndrome, a disorder of cytoplasmic organelles. Nat Genet 1996;14: 300-306.

20 Hurford MT, Sebastiano C. Hermansky-Pudlak syndrome: report of a case and review of the literature. Int J Clin Exp Pathol 2008;1: 550-554.

21 Chiang PW, Oiso N, Gautam R, Suzuki T, Swank RT, Spritz RA. The Hermansky-Pudlak syndrome 1 (HPS1) and HPS4 proteins are components of two complexes, BLOC- 3 and BLOC-4, involved in the biogenesis of lysosome-related organelles. J Biol Chem 2003; 278:20332-20337.

22 Huizing M, Scher CD, Strovel E, Fitzpatrick DL, Hartnell LM, Anikster Y, Gahl WA. Nonsense mutations in ADTB3A cause complete deficiency of the $\beta 3 \mathrm{~A}$ subunit of adaptor complex-3 and severe Hermansky-Pudlak syndrome type 2. Pediatr Res 2002;51:150-158.

23 Carter BW. Hermansky-Pudlak syndrome complicated by pulmonary fibrosis. Proc (Bayl Univ Med Cent) 2012;25:76-77.

24 Wasmeier C, Romao M, Plowright L, Bennett DC, Raposo G, Seabra MC. Rab38 and Rab32 control post-Golgi trafficking of melanogenic enzymes. J Cell Biol 2006;175:271-281.

25 Mumford AD, Frelinger AL III, Gachet C, Gresele P, Noris P, Harrison P, Mezzano D. A review of platelet secretion assays for the diagnosis of inherited platelet secretion disorders. Thromb Haemost 2015;114: $14-25$.

26 Ikawa $Y$, Hess R, Dorward H, Cullinane AR, Huizing M, Gochuico BR, Gahl WA, Candotti F. In vitro functional correction of HermanskyPudlak syndrome type-1 by lentiviral-mediated gene transfer. Mol Genet Metab 2015;114:62-65.

27 Zhang L, Yu K, Robert KW, DeBolt KM, Hong N, Tao JQ, Fukuda M, Fisher AB, Huang S. Rab38 targets to lamellar bodies and normalizes their sizes in lung alveolar type II epithelial cells. Am J Physiol Lung Cell Mol Physiol 2011;301:L461-L477.

28 Shotelersuk V, Gahl WA. Hermansky-Pudlak syndrome: models for intracellular vesicle formation. Mol Genet Metab 1998;65:85-96.

29 Seward SL Jr, Gahl WA. Hermansky-Pudlak syndrome: health care throughout life. Pediatrics 2013;132:153-160
30 American Thoracic Society; European Respiratory Society. American Thoracic Society/European Respiratory Society international multidisciplinary consensus classification of the idiopathic interstitial pneumonias. Am J Respir Crit Care Med 2002;165:277-304.

31 Raghu G, Collard HR, Egan JJ, Martinez FJ, Behr J, Brown KK, Colby TV, Cordier JF, Flaherty KR, Lasky JA, et al.; ATS/ERS/JRS/ ALAT Committee on Idiopathic Pulmonary Fibrosis. An official ATS/ ERS/JRS/ALAT statement: idiopathic pulmonary fibrosis: evidencebased guidelines for diagnosis and management. Am J Respir Crit Care Med 2011;183:788-824.

32 Gahl WA, Brantly M, Troendle J, Avila NA, Padua A, Montalvo C, Cardona H, Calis KA, Gochuico B. Effect of pirfenidone on the pulmonary fibrosis of Hermansky-Pudlak syndrome. Mol Genet Metab 2002;76:234-242.

33 King TE Jr, Pardo A, Selman M. Idiopathic pulmonary fibrosis. Lancet 2011;378:1949-1961.

34 Phan SH. Genesis of the myofibroblast in lung injury and fibrosis. Proc Am Thorac Soc 2012;9:148-152.

35 Rouhani FN, Brantly ML, Markello TC, Helip-Wooley A, O’Brien K, Hess R, Huizing M, Gahl WA, Gochuico BR. Alveolar macrophage dysregulation in Hermansky-Pudlak syndrome type 1. Am J Respir Crit Care Med 2009;180:1114-1121.

36 Inoshima I, Kuwano K, Hamada N, Hagimoto N, Yoshimi M, Maeyama T, Takeshita A, Kitamoto S, Egashira K, Hara N. Antimonocyte chemoattractant protein-1 gene therapy attenuates pulmonary fibrosis in mice. Am J Physiol Lung Cell Mol Physiol 2004; 286:L1038-L1044.

37 Henderson NC, Mackinnon AC, Farnworth SL, Kipari T, Haslett C, Iredale JP, Liu FT, Hughes J, Sethi T. Galectin-3 expression and secretion links macrophages to the promotion of renal fibrosis. Am J Pathol 2008;172:288-298.

38 Cullinane AR, Yeager C, Dorward H, Carmona-Rivera C, Wu HP, Moss J, O'Brien KJ, Nathan SD, Meyer KC, Rosas IO, et al. Dysregulation of galectin-3: implications for Hermansky-Pudlak syndrome pulmonary fibrosis. Am J Respir Cell Mol Biol 2014;50:605-613.

39 Trimble A, Gochuico BR, Markello TC, Fischer R, Gahl WA, Lee JK, Kim Y, Burdick MD, Strieter RM, Mehrad B. Circulating fibrocytes as biomarker of prognosis in Hermansky-Pudlak syndrome. Am J Respir Crit Care Med 2014;190:1395-1401.

40 Swank RT, Novak EK, McGarry MP, Rusiniak ME, Feng L. Mouse models of Hermansky Pudlak syndrome: a review. Pigment Cell Res 1998;11:60-80.

41 Suzuki T, Li W, Zhang Q, Karim A, Novak EK, Sviderskaya EV, Hill SP Bennett DC, Levin AV, Nieuwenhuis HK, et al. Hermansky-Pudlak syndrome is caused by mutations in HPS4, the human homolog of the mouse light-ear gene. Nat Genet 2002;30:321-324.

42 Zhang Q, Zhao B, Li W, Oiso N, Novak EK, Rusiniak ME, Gautam R, Chintala S, O'Brien EP, Zhang Y, et al. Ru2 and Ru encode mouse orthologs of the genes mutated in human Hermansky-Pudlak syndrome types 5 and 6. Nat Genet 2003;33:145-153.

43 Feng GH, Bailin T, Oh J, Spritz RA. Mouse pale ear (ep) is homologous to human Hermansky-Pudlak syndrome and contains a rare "AT-AC" intron. Hum Mol Genet 1997;6:793-797.

44 Gardner JM, Wildenberg SC, Keiper NM, Novak EK, Rusiniak ME, Swank RT, Puri N, Finger JN, Hagiwara N, Lehman AL, et al. The mouse pale ear $(e p)$ mutation is the homologue of human Hermansky-Pudlak syndrome. Proc Natl Acad Sci USA 1997;94: 9238-9243.

45 Feng $L$, Seymour AB, Jiang S, To A, Peden AA, Novak EK, Zhen L, Rusiniak ME, Eicher EM, Robinson MS, et al. The $\beta 3 \mathrm{~A}$ subunit gene (Ap3b1) of the AP-3 adaptor complex is altered in the mouse hypopigmentation mutant pearl, a model for Hermansky-Pudlak syndrome and night blindness. Hum Mol Genet 1999;8:323-330.

46 Suzuki T, Li W, Zhang Q, Novak EK, Sviderskaya EV, Wilson A, Bennett DC Roe BA, Swank RT, Spritz RA. The gene mutated in cocoa mice, carrying a defect of organelle biogenesis, is a homologue of the human Hermansky-Pudlak syndrome-3 gene. Genomics 2001;78: 30-37.

47 Tang X, Yamanaka S, Miyagi Y, Nagashima Y, Nakatani Y. Lung pathology of pale ear mouse (model of Hermansky-Pudlak syndrome 1) and beige mouse (model of Chediak-Higashi syndrome): severity of giant lamellar 
body degeneration of type II pneumocytes correlates with interstitia inflammation. Pathol Int 2005;55:137-143.

48 Young LR, Pasula R, Gulleman PM, Deutsch GH, McCormack FX. Susceptibility of Hermansky-Pudlak mice to bleomycin-induced type II cell apoptosis and fibrosis. Am J Respir Cell Mol Biol 2007;37:67-74.

49 Young LR, Borchers MT, Allen HL, Gibbons RS, McCormack FX. Lungrestricted macrophage activation in the pearl mouse model of Hermansky-Pudlak syndrome. J Immunol 2006;176:4361-4368.

50 Lyerla TA, Rusiniak ME, Borchers M, Jahreis G, Tan J, Ohtake P, Novak EK, Swank RT. Aberrant lung structure, composition, and function in a murine model of Hermansky-Pudlak syndrome. Am J Physiol Lung Cell Mol Physiol 2003;285:L643-L653.

51 Mahavadi P, Korfei M, Henneke I, Liebisch G, Schmitz G, Gochuico BR, Markart P, Bellusci S, Seeger W, Ruppert C, et al. Epithelial stress and apoptosis underlie Hermansky-Pudlak syndrome-associated interstitial pneumonia. Am J Respir Crit Care Med 2010;182:207-219.

52 Young LR, Gulleman PM, Bridges JP, Weaver TE, Deutsch GH, Blackwell TS, McCormack FX. The alveolar epithelium determines susceptibility to lung fibrosis in Hermansky-Pudlak syndrome. Am J Respir Crit Care Med 2012:186:1014-1024.

53 Zhou Y, He CH, Herzog EL, Peng X, Lee CM, Nguyen TH, Gulati M, Gochuico BR, Gahl WA, Slade ML, et al. Chitinase 3-like-1 and its receptors in Hermansky-Pudlak syndrome-associated lung disease. J Clin Invest 2015;125:3178-3192.

54 Ahuja S, Knudsen L, Chillappagari S, Henneke I, Ruppert C, Korfei M, Gochuico BR, Bellusci S, Seeger W, Ochs M, et al. MAP1LC3B overexpression protects against Hermansky-Pudlak syndrome type1 -induced defective autophagy in vitro. Am J Physiol Lung Cell Mol Physiol 2016;310:L519-L531.

55 Rapaport SI. Preoperative hemostatic evaluation: which tests, if any? Blood 1983;61:229-231.

56 Witkop CJ, Krumwiede M, Sedano H, White JG. Reliability of absent platelet dense bodies as a diagnostic criterion for HermanskyPudlak syndrome. Am J Hematol 1987;26:305-311.

57 Zhou L, Schmaier AH. Platelet aggregation testing in platelet-rich plasma: description of procedures with the aim to develop standards in the field. Am J Clin Pathol 2005;123:172-183.

58 Chakradhar S. Insurance companies are slow to cover next-generation sequencing. Nat Med 2015;21:204-205.
59 Avila NA, Brantly M, Premkumar A, Huizing M, Dwyer A, Gahl WA Hermansky-Pudlak syndrome: radiography and CT of the chest compared with pulmonary function tests and genetic studies. AJR Am J Roentgenol 2002;179:887-892.

60 Brantly M, Avila NA, Shotelersuk V, Lucero C, Huizing M, Gahl WA. Pulmonary function and high-resolution CT findings in patients with an inherited form of pulmonary fibrosis, Hermansky-Pudlak syndrome, due to mutations in HPS-1. Chest 2000;117: 129-136.

61 Leitman BS, Balthazar EJ, Garay SM, Naidich DP, McCauley DI. The Hermansky-Pudlak syndrome: radiographic features. Can Assoc Radiol J 1986;37:42-45.

62 Lederer DJ, Kawut SM, Sonett JR, Vakiani E, Seward SL Jr, White JG, Wilt JS, Marboe CC, Gahl WA, Arcasoy SM. Successful bilateral lung transplantation for pulmonary fibrosis associated with the Hermansky-Pudlak syndrome. J Heart Lung Transplant 2005;24: 1697-1699.

63 Tomczyk S, Bennett NM, Stoecker C, Gierke R, Moore MR, Whitney CG, Hadler S, Pilishvili T; Centers for Disease Control and Prevention (CDC). Use of 13-valent pneumococcal conjugate vaccine and 23-valent pneumococcal polysaccharide vaccine among adults aged $\geqslant 65$ years: recommendations of the Advisory Committee on Immunization Practices (ACIP). MMWR Morb Mortal Wkly Rep 2014;63:822-825.

64 King TE Jr, Bradford WZ, Castro-Bernardini S, Fagan EA, Glaspole I, Glassberg MK, Gorina E, Hopkins PM, Kardatzke D, Lancaster L, et al.; ASCEND Study Group. A phase 3 trial of pirfenidone in patients with idiopathic pulmonary fibrosis. N Engl J Med 2014;370: 2083-2092.

65 Azuma A, Taguchi Y, Ogura T, Ebina M, Taniguchi H, Kondoh $\mathrm{Y}$, Suga M, Takahashi H, Nakata K, Sato A, et al.; Pirfenidone Clinical Study Group in Japan. Exploratory analysis of a phase III trial of pirfenidone identifies a subpopulation of patients with idiopathic pulmonary fibrosis as benefiting from treatment. Respir Res 2011; 12:143.

66 O'Brien K, Troendle J, Gochuico BR, Markello TC, Salas J, Cardona H, Yao J, Bernardini I, Hess R, Gahl WA. Pirfenidone for the treatment of Hermansky-Pudlak syndrome pulmonary fibrosis. Mol Genet Metab 2011;103:128-134. 